\title{
Conduct Disorder and the specifier callous and unemotional traits in the DSM-5
}

\author{
Floortje E. Scheepers · Jan K. Buitelaar • \\ Walter Matthys
}

Received: 15 September 2010/ Accepted: 21 November 2010/Published online: 8 December 2010

(C) The Author(s) 2010. This article is published with open access at Springerlink.com

\section{Introduction}

Preparations for the fifth edition of the Diagnostic and Statistical Manual of Mental Disorders (DSM-5) are ongoing. Publication is planned in May 2013 and as part of the developmental process the preliminary draft revisions are now available for public review on the internet (http:// www.dsm5.org).

No revisions are being suggested for the main criteria of Conduct Disorder. However, an additional specifier for callous and unemotional (CU) traits in Conduct Disorder has been proposed. Both Conduct Disorder and the mentioned specifier are also on the list of proposed disorders to be studied in DSM-5 Fields Trials.

On the DSM-5 site, the historical perspective, research basis, development and initial tests of criteria in secondary data analyses, and potential concerns about the proposed callous-unemotional specifier have been described by Frick and Moffitt [1]. Moreover, outside reviewers comments and suggestions for improvements are also published on the internet site. This paper will briefly summarize the background information described by Frick and Moffit and provides the comments on the proposed specifier in addition to those already made by outside reviewers.

F. E. Scheepers $(\square)$

Karakter, Child and Adolescent Psychiatry,

Reinier Postlaan 12, 6525 GC Nijmegen, The Netherlands

e-mail: f.scheepers@karakter.com

\section{J. K. Buitelaar}

Nijmegen, The Netherlands

W. Matthys

Utrecht, The Netherlands

\section{Proposed disorder and specifier}

Conduct Disorder

A. A repetitive and persistent pattern of behavior in which the basic rights of others or major age-appropriate societal norms or rules are violated, as manifested by the presence of three (or more) of the following criteria in the past 12 months, with at least one criterion present in the past 6 months:

Aggression to people and animals

1. often bullies, threatens, or intimidates others.

2. often initiates physical fights.

3. has used a weapon that can cause serious physical harm to others (e.g., a bat, brick, broken bottle, knife, gun).

4. has been physically cruel to people.

5. has been physically cruel to animals.

6. has stolen while confronting a victim (e.g., mugging, purse snatching, extortion, armed robbery).

7. has forced someone into sexual activity.

Destruction of property

8. as deliberately engaged in fire setting with the intention of causing serious damage.

9. has deliberately destroyed others' property (other than by fire setting).

Deceitfulness or theft

10. has broken into someone else's house, building, or car.

11. often lies to obtain goods or favors or to avoid obligations (i.e., "cons" others). 
12. has stolen items of nontrivial value without confronting a victim (e.g., shoplifting, but without breaking and entering; forgery).

Serious violations of rules

13. often stays out at night despite parental prohibitions, beginning before age 13 years.

14. has run away from home overnight at least twice while living in parental or parental surrogate home (or once without returning for a lengthy period).

15. is often truant from school, beginning before age 13 years.

B. The disturbance in behavior causes clinically significant impairment in social, academic, or occupational functioning.

C. If the individual is age 18 years or older, criteria are not met for Antisocial Personality Disorder.

\section{Code type based on age at onset}

312.81 Conduct Disorder, childhood-onset type: onset of at least one criterion characteristic of Conduct Disorder prior to age 10 years.

312.82 Conduct Disorder, adolescent-onset type: absence of any criteria characteristic of Conduct Disorder prior to age 10 years.

312.89 Conduct Disorder, unspecified onset: age at onset is not known.

\section{Specify severity}

Mild few if any conduct problems in excess of those required to make the diagnosis and conduct problems cause only minor harm to others (e.g., lying, truancy, staying out after dark without permission).

Moderate number of conduct problems and effect on others intermediate between "mild" and "severe" (e.g., stealing without confronting a victim, vandalism).

Severe many conduct problems in excess of those required to make the diagnosis or conduct problems cause considerable harm to others (e.g., forced sex, physical cruelty, use of a weapon, stealing while confronting a victim, breaking and entering).

\section{Specify with or without callous and unemotional traits}

The following characteristics ( 2 or more) are shown persistently over at least 12 months and in more than one relationship or setting. The clinician should consider multiple sources of information to determine the presence of these traits, such as whether the person self-reports them as being characteristic of him or herself and if they are reported by others (e.g., parents, other family members, teachers, peers) who have known the person for significant periods of time.

- Lack of remorse or guilt does not feel bad or guilty when he/she does something wrong (except if expressing remorse when caught and/or facing punishment).

- Callous-lack of empathy disregards and is unconcerned about the feelings of others.

- Unconcerned about performance does not show concern about poor/problematic performance at school, work, or in other important activities.

- Shallow or deficient affect does not express feelings or show emotions to others, except in ways that seem shallow or superficial (e.g., emotions are not consistent with actions; can turn emotions "on" or "off" quickly) or when they are used for gain (e.g., to manipulate or intimidate others).

\section{Background information}

Youth diagnosed under the current DSM-IV-TR criteria of Conduct Disorder reflect a very heterogeneous group considering severity, course but most importantly presumed etiology [2, 3]. This makes it difficult to focus on dysfunctional (brain) systems causing conduct behavior and investigate the effectiveness of treatment.

In adults, the importance of psychopathic traits for designating a subgroup of antisocial individuals has been long evident in clinical research $[4,5]$. These traits reflect an affective and interpersonal style of the individual (e.g., lack of empathy, lack of guilt, shallow emotions, egocentricity, callous use of others for own gain) and seem to be associated with a more severe, violent and chronic pattern of antisocial behavior [6] as well as different affective, cognitive and neurological characteristics [7]. As a consequence, the addition of a psychopathic type to the Antisocial Personality Disorder in the DSM-5 is recommended and has been proposed by the DSM-5 workgroup.

In youth, the same traits have been used to designate a subgroup, i.e., difficult or impossible to treat and has more severe symptoms of aggression. In DSM-III, these traits were hinted at in the Conduct Disorder diagnosis as "the undersocialized type". However, this subtype was not continued into the following editions of the DSM since the term undersocialized did not clearly describe the correct features of psychopathic traits and focused too much on social attachment which is not proven to be a reliable indicator for the intended subcategory of Conduct 
Disorder. The only well-validated distinction that remains in DSM-IV-TR is that between childhood-onset (onset before age 10) and adolescent-onset (absence of symptoms before age 10).

Ongoing research has continued to focus on callous and unemotional traits and has now provided extensive data supporting a specifier including these traits to be added to the Conduct Disorder diagnosis (see for reviews 8, 9). In summary, CU traits can be assessed reliably and have been demonstrated to consistently designate a subgroup within antisocial youth with a more severe and pervasive pattern of conduct problems and poorer treatment outcomes. This makes the specifier of clinical relevance. In addition, CU traits are relatively stable from childhood to early adolescence and early adulthood $[10,11]$ even when one controls for childhood conduct problems and other risk factors for antisocial behavior [12]. Finally, youth with conduct problems in combination with $\mathrm{CU}$ traits seems to have deficits in processing signs of fear and distress in others, they seem to be less sensitive to punishment and show more fearless or thrill seeking behavior. From a biological perspective, amygdala hyporeactivity has been found in response to fearful faces in antisocial youth with CU traits $[13,14]$ as possible underlying dysfunctional mechanism to account for these findings. Particularly important is the genetic influence that was found to be strong in conduct problems in combination with $\mathrm{CU}$ traits (heritability of 0.81 ) with little influence of shared environment $[15,16]$. In contrast, in antisocial youth without $\mathrm{CU}$ traits genetic influence is modest (heritability of 0.30) and environmental influence is substantial. These findings remained after controlling for impulsivity-hyperactivity scores or severity of conduct problems.

\section{Comments}

Discussing possible concerns about the proposed specifier Frick and Moffit [1] considered the potential harmful labeling effects of the CU subgroup. However, the term Conduct Disorder in itself seems to have similar associations and the impact will largely depend on the way clinicians use the term CU traits. Another concern of Frick, Moffit, and previous commentators is whether traits can be assessed reliably by a clinician. This is, of course, relevant to all symptoms in the DSM classification system and needs to be tested in the field trials. One not mentioned tricky problem in the assessment of $\mathrm{CU}$ traits could be the fact that the most of these traits reflect interpersonal thoughts and feelings of guilt, remorse or empathy. These traits are, therefore, more difficult to observe by outsiders in contrast with most of the externalizing behavior that is scored to meet the criteria of Conduct Disorder. One potential conclusion is that only self-report assessments are reliable in measuring $\mathrm{CU}$ traits. However, in the literature different sources have been used to score CU traits (parents, teachers, clinicians and self-report ratings) all of which seem to be reliable. This suggests that clinicians should be capable of accurately scoring CU traits. Another problem in our opinion in the assessment of the $\mathrm{CU}$ criteria could be the lack of specificity and subjectivity of the third and forth criteria. For example, being unconcerned about (school) performance and shallow or deficient affect could also be related to depressed mood or overburdening. Poor performance in itself is also difficult to measure particularly if performances are good enough to pass exams but below expected level of performance of the individual person.

Some of the external reviewers expressed concern about the appropriateness of making the specifier contingent on Conduct Disorder, rather than maintaining some independence between callous-unemotional traits and antisocial behavior. This reflects the fact that these traits are also found in non-antisocial individuals and in children with other diagnosis like Oppositional Defiant Disorder. However, this can be modified by our thesis that, in order to limit the harmful labeling effects or creating a pejorative term in CU traits, the condition of meeting full criteria for Conduct Disorder is precisely what is needed. Also commented on are the limited immediate practical implications for clinicians as few studies have so far addressed the treatment of youths with Conduct Disorder and CU traits. This could, in our point of view, also be seen as a potential strength since the first step in developing an effective intervention is to clearly describe the target group. For example, most of the evidence-based interventions that are indicated for Conduct Disorder such as parent management training, functional family treatment or multiple system therapy focus on parents or social networks. Since environmental factors play a major role in Conduct Disorder without CU traits these interventions may, therefore, be effective for this group. However, in Conduct Disorder with CU traits, environmental factors play a less dominant role which could explain the fact that these interventions are found to be less effective. Maybe in youth with Conduct Disorder and CU traits, which is associated with a pronounced genetic influence, focusing on biological systems in the child itself is a much more promising perspective from which to develop new treatment strategies. On the other hand, it has been found that the heritability coefficient for aggression among 3-year olds is 69\% [17]. Similarly, the heritability coefficient for antisocial behaviour that is pervasive across settings among 5-year olds is $82 \%$ [18]. Thus, the effect of hereditary factors seems to be larger in preschoolers than in school children, adolescents and adults. This is in line with the previous described well- 
validated distinction that remained in DSM-IV-TR between childhood-onset and adolescent-onset. It might be that genetic factors play a more important role in the initiation of the disorders in the early childhood than in the maintenance of the disorders in the late childhood and adolescence when the impact of environmental factors increases. It will be interesting to investigate the relation between $\mathrm{CU}$ traits and age of onset of conduct problems in order to further unravel genetic influence on expression and/or duration of symptoms.

Lack of empathy, the role of the amygdala, and other neurobiological influences could all be important research subjects for future research if it is possible to differentiate a more specific subgroup in the classification of Conduct Disorder. It has been suggested that fearlessness and reduced amygdala functioning are specifically associated with the CU traits [9]. It is, however, unclear whether these and other neurobiological characteristics that have been found in $\mathrm{CD}$ youth with $\mathrm{CU}$ traits are specifically associated with the $\mathrm{CU}$ traits or with the combination of $\mathrm{CD}$ and CU traits. For example, reduced electrodermal activity in anticipation of, and in response to, an aversive stimulus has been found in psychopathy-prone adolescent boys. However, differences did not emerge when antisocial nonpsychopathic boys were compared with antisocial psychopathy-prone boys. Thus, it seems likely that it is the antisocial behaviour component of psychopathy that is associated with skin conductance hyporesponsivity and not CU traits in particular [19]. In line with this, various fMRI studies have found reduced amygdala reactivity in DBD/ $\mathrm{CD}$ youth with $\mathrm{CU}$ traits in comparison to healthy controls, but in these studies comparisons were not made between DBD/CD youth with and without CU traits [13, 14]. Finally, in a prospective study, fear conditioning using electrodermal responsivity was assessed in children at ages 3, 4, 5, 6 and 8. It was shown that poor electrodermal fear conditioning from ages 3 to 8 years is associated with aggression at age 8 [20]. Furthermore, it appeared that poor fear conditioning at age 3 predisposes to crime at age 23 [21]. Thus, it seemed possible to predict aggression and crime using fear conditioning data in early childhood without including CU trait data. However, since CU traits were not included in this study it is possible that these traits are related to fear conditioning data and thus indeed play a role. In summary, further research is needed to demonstrate the specificity of neurobiological characteristics of $\mathrm{CU}$ traits.

Finally, another added comment on the current specifier for severity in Conduct Disorder in the DSM-IV-TR is that severity is based on the extent of conduct problems. However, the described conduct problems are predominantly externalizing behavior symptoms in relation to others (violating basic rights of others, societal norms or rules) and, therefore, not recognizable as patient characteristics without a societal context. Moreover, as a consequence, when conduct behavior is more covert or applied in a manipulative way this could undeserved be diagnosed as a mild type of Conduct Disorder while in fact it concerns a more psychopathic (severe) type. When international criteria, like CU traits, are used to describe a more genetically loaded subtype of Conduct Disorder outside the societal context, this will further facilitate to investigate the cognitive and biologic mechanisms underlying the symptoms of this disorder. There is another advantage of the proposed specifier of CU traits in Conduct Disorder. In the current version of the DSM-IV-TR, there is no possibility to classify the explicit lack of empathy that is sometimes found in youth with severe delinquent behavior. In forensic reports, this is sometimes solved by diagnosing a co-morbid Pervasive Developmental Disorder Not Other Specified (PDD-NOS). This, of course, confuses research findings in the autistic (forensic) field and could also stigmatize patients with an autistic disorder. However, the reverse may also occur, i.e., diagnosing CD with CU traits when actually PDD-NOS with CD would be more appropriate as a diagnose.

In summary; there seems to be substantial research literature supporting the importance of CU traits in identifying an important subgroup of antisocial youth. The implementation of a CU specifier within DSM-5 could help to specify diagnosis and further investigate etiology and treatment possibilities in Conduct Disorder and would also be more in line with a biological genetic basis of axis I disorders.

Open Access This article is distributed under the terms of the Creative Commons Attribution Noncommercial License which permits any noncommercial use, distribution, and reproduction in any medium, provided the original author(s) and source are credited.

\section{References}

1. Frick PJ, Moffitt TE (2010) A proposal to the DSM-V Childhood Disorders and the ADHD and Disruptive Behavior Disorders Work Groups to include a specifier to the Diagnosis of Conduct Disorder based on the presence of Callous-unemotional Traits. American Psychiatric Association, USA, pp 1-36

2. Frick PJ (2006) Developmental pathways to conduct disorder. Child Adolesc Psychiatr Clin N Am 15:311-331

3. Moffit TE, Arseneault L, Jaffee SR, Kim-Cohen J, Koenen KC, Odgers CL, Slutske WS, Viding E (2008) DSM-V conduct disorder: research needs for an evidence base. J Child Psychol Psychiatry 49:3-33

4. Cleckley HM (1988) The mask of sanity. Mosby, St Louis

5. Hare RD (1993) Without conscience: the disturbing world of the psychopaths among us. Guilford, New York

6. Hare RD, Neumann CS (2008) Psychopathy as a clinical construct. Ann Rev Clin Psychol 4:217-246 
7. Patrick CJ (2007) Getting to the heart of psychopathy. In: Herves H, Yuille JC (eds) The psychopathy: theory, research and practice. Mahwah, Erlbaum, pp 207-252

8. Frick PJ, Dickens C (2006) Current perspectives on conduct disorder. Curr Psychiatry Rep 8:59-72

9. Frick PJ, White SF (2008) Research review: the importance of callous-unemotional traits for developmental models of aggressive and antisocial behavior. J Child Psychol Psychiatry 49:359-375

10. Obradovic J, Pardini D, Long JD, Loeber R (2007) Measuring interpersonal callousness in boys from childhood to adolescence: an examination of longitudinal invariance and temporal stability. J Clin Child Adolesc Psychol 36:276-292

11. Loney BR, Taylor J, Butler MA, Iacono WG (2007) Adolescent psychopathy features: 6-years stability and the prediction of externalizing symptoms during the transition to adulthood. Aggress Behav 33:242-252

12. Burke JD, Loeber R, Lahey BB (2007) Adolescent conduct disorder and interpersonal callousness as predictors of psychopathy in adults. J Clin Child Adolesc Psychol 36:334-346

13. Jones AP, Laurens KL, Herba C, Barker G, Viding E (2009) Amygdalahypoactivity to fearful faces in boys with conduct problems and callous-unemotional traits. Am J Psychiatry 166:95-102

14. Marsh AA, Finger EC, Mitchell DG, Reid ME, Sims C, Kosson DS, Towbin KE, Leibenluft E, Pine DS, Blair RJ (2008) Reduced amygdala response to fearful expressions in children and adolescents with callous-unemotional traits and disruptive behavior disorders. Am J Psychiatry 165:712-720

15. Viding E, Blair JR, Moffitt TE, Plomin R (2005) Evidence for substantial genetic risk for psychopathy in 7-year-olds. J Child Psychol Psychiatry 46:592-597

16. Viding E, Jones A, Frick P, Moffitt TE, Plomin R (2008) Heritability of antisocial behavior at age nine: do callous-unemotional traits matter? Dev Sci 11:17-22

17. Van den Oord EJCG, Verhulst FC, Boomsma DI (1996) A genetic study of maternal and paternal ratings of problem behaviors in 3-year-old twins. J Abn Psychol 105:349-357

18. Arsenault L, Moffitt TE, Caspi A, Taylor A, Rijsdijk FV, Jaffee SR, Ablow JC, Measelle JR (2003) Strong genetic effects on cross-situational antisocial behaviour among 5-year old children according to mothers, teachers, examiner-observers, and twinreports. J Child Psychol Psychiatry 44:832-848

19. Fung MT, Raine A, Loeber R, Lynam DR, Steinhauer SR, Venables PH, Stouthamer-Loeber M (2005) Reduced electrodermal activity in psychopathy-prone adolescents. J Abn Psychol 114:187-196

20. Gao Y, Raine A, Venables PH, Dawson ME, Mednick SA (2010a) Reduced electrodermal fear conditioning from ages 3 to 8 years is associated with aggressive behaviour at age 8 years. J Child Psychol Psychiatry 51:550-558

21. Gao Y, Raine A, Venables PH, Dawson ME, Mednick SA (2010b) Association of poor childhood fear conditioning and adult crime. Am J Psychiatry 167:56-60 